\title{
Competing Demands or Clinical Inertia: The Case of Elevated Glycosylated Hemoglobin
}

\author{
Michael L. Parchman, MD, MPH', \\ Jacqueline A. Pugh, $M D^{1,3}$ \\ Raquel L. Romero, $M D^{1,2}$ \\ Krista W. Bowers, MD ${ }^{3}$ \\ 'VERDICT Health Services Research \\ Center, South Texas Veterans Health Care \\ System, San Antonio, Tex \\ ${ }^{2}$ Department of Family \& Community Med- \\ icine, University of Texas Health Science \\ Center-San Antonio, San Antonio, Tex \\ ${ }^{3}$ Department of Medicine, University of \\ Texas Health Science Center-San Antonio, \\ San Antonio, Tex
}

Conflicts of interest: none reported

\section{CORRESPONDING AUTHOR}

Michael L. Parchman, MD, MPH South Texas Veterans Health Care System VERDICT 11C6

7400 Merton Minter Blvd

San Antonio, TX 78229-4404

parchman@uthscsa.edu

\begin{abstract}
PURPOSE This study aimed to examine the contribution of competing demands to changes in hypoglycemic medications and to return appointment intervals for patients with type 2 diabetes and an elevated glycosylated hemoglobin $\left(A_{1 c}\right)$ level.
\end{abstract}

METHODS We observed 211 primary care encounters by adult patients with type 2 diabetes in 20 primary care clinics and documented changes in hypoglycemic medications. Competing demands were assessed from length of encounter, number of concerns patients raised, and number of topics brought up by the clinician. Days to the next scheduled appointment were obtained at patient checkout. Recent $A_{1 c}$ values and dates were determined from the chart.

RESULTS Among patients with an $A_{1 c}$ level greater than 7\%, each additional patient concern was associated with a 49\% (95\% confidence interval, 35\%-60\%) reduction in the likelihood of a change in medication, independent of length of the encounter and most recent level of $A_{1 c}$. Among patients with an $A_{1 c}$ level greater than $7 \%$ and no change in medication, for every additional minute of encounter length, the time to the next scheduled appointment decreased by 2.8 days $(P=.001)$. Similarly, for each additional $1 \%$ increase in $A_{1 c}$ level, the time to the next scheduled appointment decreased by 8.6 days $(P=.001)$.

CONCLUSIONS The concept of clinical inertia is limited and does not fully characterize the complexity of primary care encounters. Competing demands is a principle for constructing models of primary care encounters that are more congruent with reality and should be considered in the design of interventions to improve chronic disease outcomes in primary care settings.

Ann Fam Med 2007;5:196-201. DOI: 10.1370/afm.679.

\section{INTRODUCTION}

$\mathrm{A}$ 1though tight glucose control can prevent or delay the onset of complications in patients with type 2 diabetes mellitus, ${ }_{1}^{1-3}$ optimal control is frequently not achieved. ${ }^{4-6}$ Recently, poor glucose control has been attributed to so-called clinical inertia on the part of physicians, defined as "recognition of the problem, but failure to act."7-12 Some have even proposed methods for a measure of clinical inertia as a quality of care indicator. ${ }^{13}$ The phenomenon of clinical inertia has been difficult to study because of the paucity of data on the content of the patient-physician encounter. All published studies of clinical inertia to date have used administrative or medical record data.

An alternative explanation for failure to intensify therapy despite poor glucose control is the presence of competing demands. ${ }^{14-18}$ Encounters are bounded by a time constraint within which multiple diagnoses, problems, and patient concerns compete with each other for a place on the agenda. Physicians and patients prioritize demands and only deal with the most pressing or symptomatic problem. ${ }^{14}$ Problems perceived to be less urgent, for example, intensifying medication therapy for poorly controlled glycosylated hemoglobin $\left(A_{1 c}\right)$ levels, may not be addressed and may be deferred to future encounters. Competing demands have been shown to 
interfere with depression care ${ }^{16}$ mammography screening ${ }_{1}{ }^{17}$ and tobacco cessation counseling ${ }_{1}^{15}$ and they limit the treatment of unrelated medical disorders. ${ }^{18} \mathrm{~A}$ primary determinant of intensification of therapy for an elevated $\mathrm{A}_{1 \mathrm{c}}$ level may thus be the presence of competing demands during the encounter, not clinical inertia. If competing demands are present, we hypothesize that for patients with an elevated $A_{1 c}$ level:

1. As the length of the encounter decreases, the likelihood of a change in hypoglycemic medication will decrease.

2. As the number of patient concerns increases within the bounds of the length of the encounter, the likelihood of a change in medication will decrease.

3. When there is no change in medications, the number of days to the next scheduled appointment will be inversely associated with the length of the current encounter and the most recent $\mathrm{A}_{1 \mathrm{c}}$ level.

\section{METHODS}

\section{Study Design and Recruitment}

The Direct Observation of Diabetes Care Study was begun in 2002 with the primary aim of conducting an in-depth examination of the care delivered to patients with type 2 diabetes across a diversity of primary care settings. Details of the study design have been published elsewhere. ${ }^{19}$ The design was cross-sectional and observational: no interventions were performed, and participants received their usual care from their primary care physician. The study took place in 20 primary care clinics with 45 primary care physicians. None of the physicians were trainees. Clinics were recruited in a snowball fashion with an attempt to identify and recruit primary care settings wherein people with type 2 diabetes are most likely to seek care: solo practice physician clinics (11 clinics, 11 physicians), group practice settings (3 clinics, 10 physicians), community health centers (1 clinic, 1 physician), Veterans Affairs primary care clinics ( 2 clinics, 11 physicians), and city-county health clinics for uninsured patients ( 3 clinics, 12 physicians).

\section{Patients and Data Collection}

Within each clinic, consecutive patients seeking care with an established diagnosis of type 2 diabetes were recruited to participate in the study. None of the patients approached declined participation. A trained observer accompanied the first 8 to 10 consenting patients in each clinic to the examination room and directly observed the encounter. In the final sample, the range of patients per clinic was 8 to 10 and the range per physician was 1 to 10 . The encounter was audio recorded, and a checklist of services performed was completed to record the length and content of each encounter. After each encounter, patients completed a survey form and their medical record was abstracted.

\section{Definition of Variables}

The observer noted and recorded any increase in dose or any addition or substitution of an oral hypoglycemic agent or insulin during the encounter. We defined these events as changes in medication. The length of encounter was defined as the number of minutes the clinician was present in the examination room with the patient. The observer listened carefully to the exchange between the patient and physician, and recorded any symptom or complaint brought up by the patient and any topic brought up by the physician. A symptom or complaint was any type of physical or emotional distress expressed verbally by the patient. For example, in one encounter, the patient reported new-onset knee pain, and this was counted as 1 symptom or complaint. We called these collectively patient concerns. The most recent value of $A_{1 c}$ in the medical record was used to evaluate glycemic control at the time of the encounter. Length of time between the observed encounter and the most recent $A_{1 c}$ measurement was also noted out of concern that physicians may not act to intensify therapy if values are too distant in time. Because the trend in $A_{1 c}$ value is often used in making clinical decisions about changes in medications, we created a variable to indicate whether the most recent $A_{1 c}$ value was worse than the previous value.

\section{Analysis}

We used descriptive statistics to examine the central tendency of the observed variables. A Student $t$ test was used to evaluate differences in means. Random effects logistic regression models were used to adjust for the clustering of patients within clinics. We chose clinic as the level of analysis because of the sparse number of patients per physician and because in 12 of the 20 clinics, only 1 physician participated in the study. For the first 2 hypotheses, we included only patients with an $\mathrm{A}_{1 \mathrm{c}}$ level greater than $7 \%$. Change in medication (yes or no) was the dependent variable, and a Bournelli distribution was used because of the dichotomous nature of this variable. To test the third hypothesis, the number of days to the next scheduled appointment was the dependent variable. This model included only patients with both an $\mathrm{A}_{1 \mathrm{c}}$ level greater than $7 \%$ and no change in medication. We did not enter any explanatory variables at the clinic level in either model. Descriptive and univariate statistics were performed with SPSS 13.0 (SPSS Inc, Chicago, Ill). ${ }^{20}$ All random effects models were performed using HLM 6.0 (Scientific Software International, Inc, Lincolnwood, Ill). ${ }^{21}$

Finally, there was a possibility that the interaction 
style of the physician during the encounter might influence the likelihood of a change in medication. For example, if some physicians tended to address $A_{1 c}$ results and the need for a change in medication early during the encounter, they might have been less likely to elicit patient concerns. We evaluated this possibility in a separate analysis to determine whether these discussions occurred earlier in encounters with a medication change. Using the Davis Observation Codes, ${ }^{22}$ we examined the proportion of the encounter that occurred before the first of 2 behaviors appeared: (1) an "evaluation or feedback" code for when the physician tells the patient about results of recent test results, such as an $A_{1 c}$ level, and (2) the "planning treatment" for when the physician and patient discussed a treatment plan, such as a change in medication. In addition, we used the Davis Observation Codes to compare the amount of time spent discussing diet, exercise, and medication adherence between patients with and without a change in medication.

This study was reviewed and approved by the institutional review board at the University of Texas Health Science Center, San Antonio, Tex.

\section{RESULTS}

A total of 211 patient encounters were observed across the 20 clinics. Of these, 177 patients had an $A_{1 c}$ value recorded in their medical record before the encounter. Of the 18 patients without an $A_{1 c}$ value, 8 were new patients and 1 received diabetes care from an outside specialist, resulting in 25 patients with missing $A_{1 c}$ values. There were no differences in age, sex, race/ethnicity, or length of relationship with current primary care physician between those with and without an $\mathrm{A}_{1 \mathrm{c}}$ value in the chart. None of the clinics had more than 2 patients with a missing value. For those with an $A_{1 c}$ value, $35.6 \%$ had been obtained within the past 30 days before the encounter and $46.9 \%$ had been obtained within the last 60 days. All patients reported that the physician they saw was their usual primary care physician. The length of their current relationship with their usual physician was 54.9 months (SD, 56.4), approximately 6 years. Characteristics of all patients and encounters observed are shown in Table 1. A change in oral medications occurred in $26.7 \%$ of encounters. As the $A_{1 c}$ value increased, the percentage of encounters with a change in medication also increased. All subsequent analyses are limited to the 98 encounters wherein the $A_{1 c}$ value was greater than $7 \%$.

Compared with encounters without a change in medication, those with a change were longer, involved fewer patient concerns, and had higher most recent $\mathrm{A}_{1 \mathrm{c}}$ values (Table 2). There was no difference in the
Table 1. Characteristics of Patients and Encounters $(\mathrm{N}=177)$

\begin{tabular}{lc}
\hline Characteristic & Mean (SD) or \% \\
\hline Age, years & $59.0(13.3)$ \\
Female, \% & 51.3 \\
Hispanic, \% & 59.2 \\
Hemoglobin $A_{1 c}$ level & 55.4, \\
$>7.0 \%$ & 34.5 \\
$>8.0 \%$ & $17.0(8.4)$ \\
Length of encounter, minutes & $2.0(1.9)$ \\
Number of patient concerns & \\
Encounters with a change in hypoglycemic & \\
medication, \% & 26.7 \\
All & 35.6 \\
With hemoglobin $\mathrm{A}_{1 c}$ level >7\% & 42.9 \\
With hemoglobin $\mathrm{A}_{1 \mathrm{c}}$ level >8\% & 46.4 \\
With hemoglobin $\mathrm{A}_{1 \mathrm{c}}$ level >9\% & $60.9(43.2)$ \\
Days to next scheduled appointment & \\
\hline Hemoglobin $\mathrm{A}_{1 c}=$ glycosylated hemoglobin.
\end{tabular}

proportion of the encounter spent discussing lifestyle changes or medication adherence between those with and without a change in medication. Patients with a change in medication were taking more medications on a long-term basis than those without a change. Having a most recent $\mathrm{A}_{\mathrm{c}}$ level that was worse than the previous value was not associated with a change in medication (odds ratio $=1.09 ; 95 \%$ confidence interval, 0.59-2.03). Physicians were not more likely to order an $\mathrm{A}_{1 \mathrm{c}}$ measurement if there was no change in medications, even if the last $A_{1 c}$ level was more than 60 days ago (data not shown). Nor was there any evidence that physician practice style was associated with the likelihood of a change in medication: there were no significant differences between encounters with and without a change in medication in the proportion of encounter time until evaluation and feedback of test results or until discussion of planning treatment occurred (Table 2).

For each additional patient concern, there was a $49 \%$ reduction in the likelihood of a change in medication (Table 3 ). The results did not change if patient age, sex, or a variable indicating that the most recent $\mathrm{A}_{1 \mathrm{c}}$ level was worse than the one before was included in the model. We performed a sensitivity analysis on the relationship between number of patient concerns and change in medication for this group. Once the number of patient concerns exceeded 4, none of the encounters had a change in medication. The analysis was repeated for patients with an $A_{1 c}$ level of $8 \%$ or higher with similar results (Table 3 ). The figure displays the relationships between change in medication, length of encounter, and occurrence of any patient concern (yes or no).

For encounters with no change in medication, the 
number of days to the next scheduled appointment was associated with the length of the encounter $(P=.001)$. For each additional 1 minute of encounter length, the number of days to the next appointment decreased by 2.8 days. In addition, for each additional $1 \%$ increase in $A_{1 c}$ value, the number of days to the next scheduled appointment decreased by 8.6 days $(P=.001)$. There was no relationship between length of encounter and number of days to the next scheduled appointment for encounters with a change in medication. Nor was there any difference in the number of days to the next appointment between encounters with and without a change in medication (data not shown).

\section{DISCUSSION}

The concept of clinical inertia does not adequately characterize the complexity of the primary care encounter. Instead, competing demands during the encounter, as observed by the number of patient concerns, is a more accurate description. As the number of patient concerns increased, the likelihood of a change in medication decreased, independent of the length of the encounter, the most recent $A_{1 c}$ level, the number of topics brought up by the clinician, the length of time since the last $A_{1 c}$ measurement, and the trend in $A_{1 c}$ levels. Detailed analysis of the content of the visit failed to support the possibility that physician interaction

style explained the association between number of patient concerns and the likelihood of a change in medication.

As previously mentioned, soft reasons to avoid intensification of therapy are cited as an explanation for clinical inertia. For example, clinicians may substitute a discussion of self-care activities for therapy intensification. Our data fail to support this explanation: there was no difference in the amount of encounter time spent discussing self care between encounters with and without a change in medication for patients whose $A_{1 c}$ value was greater than $7 \%$. It also does not appear that physicians are deferring a decision to change medications because the most recent $A_{1 c}$ value was obtained too long ago: the number of days since the last $A_{1 c}$ measurement was not a significant predictor of a change in medication.

Another explanation cited for clinical inertia is "... unawareness on the part of the clinician about the limitations of the care they provide." ${ }^{18}$ Our findings also fail to support this explanation: when there was no change in medication, as length of encounter increased, days to next appointment decreased, suggesting that when the agenda of the encounter was 


\section{Figure 1. Percentage of patients with a change in medication, by encounter length and presence of patient concerns.}

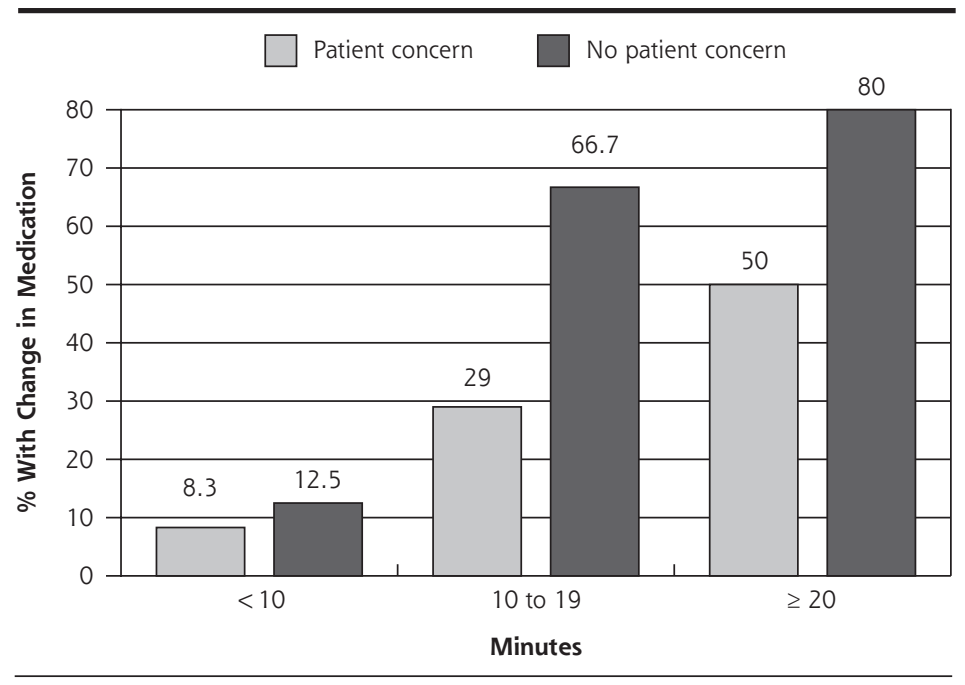

Note: $\chi^{2}$ across Patient concern: $7.26(P=.03) ; \chi^{2}$ across No patient concern: $6.93(P=.03)$

encounters are analyzed in administrative data, approximately $70 \%$ of patients with elevated $\mathrm{A}_{1 \mathrm{c}}$ levels do have a change in therapy within 6 months. ${ }^{23}$

Why should it matter whether we use the term clinical inertia or competing demands in describing primary care encounters? To understand why a change is or is not made in medication in the face of inadequate glucose control or any other observed phenomenon in a scientific manner, we develop an abstract representation, or a model, that helps us simplify reality so that we can understand what we observe. ${ }^{24}$ To construct a model, we use general principles that are rules for constructing models. One example of such a principle is that of natural selection. Different principles result in very different models. The empirical question that one must then answer is how

full, clinicians were aware of the need to address the elevated $A_{1 c}$ level and requested that the patient return sooner. In addition, when there was no change in medication, encounters with higher $A_{1 c}$ values had shorter return times, again suggestive that clinicians were aware of the elevated $\mathrm{A}_{1 \mathrm{c}}$ value but deferred action to the next encounter. This finding is consistent with those of a recent longitudinal study of intensification of therapy for poor glucose control: among patients with an $\mathrm{A}_{1 \mathrm{c}}$ value exceeding $8 \%$, therapy was intensified in $58.1 \%$ within 3 months and in $69.7 \%$ within 6 months. ${ }^{23}$

Some limitations exist in interpreting findings from this study. One is the potential for change in physician behavior because of the presence of an observer in the examination room during the encounter. If such a performance bias existed, it would most likely have resulted in a bias away from the null hypotheses in this study. That is, given that the purpose of the study as explained to physicians was to "... examine predictors of quality and outcomes of care for patients with type 2 diabetes," physicians may have focused more on following current evidence-based guidelines with an observer in the room. On the other hand, prior studies of clinical inertia have been limited to medical record or administrative data. ${ }^{7-12}$ Our use of direct observation is particularly well suited to the study of clinical inertia and is a strength of this study. For example, none of the prior studies of clinical inertia measured length of encounter. A second limitation is the lack of follow-up data. Although patients were scheduled to return sooner if there was no change in medication, we were unable to ascertain whether any action was taken in the subsequent encounter. As mentioned above, when follow-up well one model developed with one principle fits the intended aspects of the real world compared with a different model developed using a different principle. In this study, the principle of competing demands, when applied to a model of the clinical encounter, results in a better fit than a model constructed using the principle of clinical inertia. Studies conducted using a model based on the principle of clinical inertia thus are likely to provide misleading results, and interventions designed based on this principle are likely to be ineffective.

The principle of competing demands is also consistent with recent observations that primary health care delivery demonstrates properties of a complex adaptive system. ${ }^{25}$ These systems have nonlinear dynamic patterns over time, contrary to the notion that encounters are linear and mechanistic and follow the rules of Newtonian physics, such as demonstrating the property of inertia. Newtonian inertia states that objects at rest will remain at rest and those in motion will remain in motion until acted on by a force. Our findings suggest that primary care encounters are neither static nor linear, but instead are filled with multiple activities, suggesting movement. The problem with calculating a vector for movement (velocity plus direction) is that we do not know in which direction the agents in the system (physician and patient) are moving. It is therefore somewhat pejorative to assert that physicians are moving in the wrong direction when they are addressing problems other than a change in medication for glucose control as suggested by the clinical inertia model.

The comprehensiveness of the care provided by primary care clinicians to patients with one or more chronic illness is a strength of primary care but is also 
a balancing act that requires prioritization and goal setting by both patient and physician during each encounter in a manner that takes into consideration patient resources, expectations, and willingness to intensify therapy. ${ }^{26-28}$ In contrast, much of the work published using the term clinical inertia has been from the limited perspective of diabetes specialists interested only in the quality of diabetes care without incorporating any evaluation of care for other concurrent problems. Development of models to advance our understanding of the delivery of primary care to patients with multiple chronic illnesses, including type 2 diabetes, should incorporate the principle of competing demands and complex adaptive system principles, rather than clinical inertia, as should interventions designed to improve outcomes for these patients in primary care settings. ${ }^{29}$

To read or post commentaries in response to this article, see it online at http://www.annfammed.org/cgi/content/full/5/3/196.

Key words: Diabetes mellitus, type 2; hemoglobin A, glycosylated; ambulatory care; primary care; health care delivery; health services research; quality of care; practice-based research networks; office visits

Submitted July 2, 2006; submitted, revised, October 20, 2006; accepted November 18, 2006.

These results were presented, in part, at the North American Primary Care Research Group Meeting, October 2005, Quebec City, Quebec.

Funding support: This research was supported by the Agency for Healthcare Research and Quality (grant K08 HS013008-02) and the Department of Veterans Affairs, Veterans Health Administration, Health Services Research and Development Service.

Disclaimer: The views expressed in this article are those of the authors and do not necessarily represent the views of the Department of Veterans Affairs.

Acknowledgments: We would like to express our appreciation to the members of the South Texas Ambulatory Research Network (STARNet) for their participation in this study.

\section{References}

1. Intensive blood-glucose control with sulphonylureas or insulin compared with conventional treatment and risk of complications in patients with type 2 diabetes (UKPDS 33). UK Prospective Diabetes Study (UKPDS) Group. Lancet. 1998;352(9131):837-853.

2. Selvin E, Marinopoulos S, Berkenblit G, et al. Meta-analysis: glycosylated hemoglobin and cardiovascular disease in diabetes mellitus. Ann Intern Med. 2004;141(6):421-431

3. American Diabetes Association. Clinical Practice Recommendations 2005. Diabetes Care. 2005;28(Suppl 1):S1-S79.

4. Harris MI, Eastman RC, Cowie CC, Flegal KM, Eberhardt MS. Racial and ethnic differences in glycemic control of adults with type 2 diabetes. Diabetes Care. 1999;22(3):403-408.

5. Imperatore G, Cadwell BL, Geiss L, et al. Thirty-year trends in cardiovascular risk factor levels among US adults with diabetes: National Health and Nutrition Examination Surveys, 1971-2000. Am J Epidemiol. 2004;160(6):531-539.
6. Putzer GJ, Ramirez AM, Sneed K, et al. Prevalence of patients with type 2 diabetes mellitus reaching the American Diabetes Association's target guidelines in a university primary care setting. South Med J. 2004;97(2):145-148.

7. Cook CB, Ziemer DC, El-Kebbi IM, et al. Diabetes in urban AfricanAmericans. XVI. Overcoming clinical inertia improves glycemic control in patients with type 2 diabetes. Diabetes Care. 1999;22(9):1494-1500.

8. Phillips LS, Branch WT, Cook CB, et al. Clinical inertia. Ann Intern Med. 2001;135(9):825-834

9. Grant RW, Cagliero E, Dubey AK, et al. Clinical inertia in the management of type 2 diabetes metabolic risk factors. Diabet Med. 2004;21(2):150-155.

10. Kennedy AG, MacLean CD. Clinical inertia: errors of omission in drug therapy. Am J Health Syst Pharm. 2004;61(4):401-404.

11. Phillips LS, Ziemer DC, Doyle JP, et al. An endocrinologist-supported intervention aimed at providers improves diabetes management in a primary care site: improving primary care of African Americans with diabetes (IPCAAD) 7. Diabetes Care. 2005;28(10):2352-2360.

12. Shah BR, Hux JE, Laupacis A, Zinman B, van Walraven C. Clinical inertia in response to inadequate glycemic control: do specialists differ from primary care physicians? Diabetes Care. 2005;28(3):600-606.

13. Berlowitz DR, Ash AS, Glickman M, et al. Developing a quality measure for clinical inertia in diabetes care. Health Serv Res. 2005; 40(6 Pt 1):1836-1853.

14. Jaen CR, Stange KC, Nutting PA. Competing demands of primary care: a model for the delivery of clinical preventive services. J Fam Pract. 1994;38(2):166-171.

15. Jaen $C R$, Mcllvain $H$, Pol $L$, et al. Tailoring tobacco counseling to the competing demands in the clinical encounter. J Fam Pract. 2001;50(10):859-863.

16. Nutting PA, Rost K, Smith J, Werner JJ, Elliot C. Competing demands from physical problems: effect on initiating and completing depression care over 6 months. Arch Fam Med. 2000;9(10):1059-1064.

17. Nutting PA, Baier M, Werner JJ, et al. Competing demands in the office visit: what influences mammography recommendations? J Am Board Fam Pract. 2001;14(5):352-361.

18. Redelmeier DA, Tan SH, Booth GL. The treatment of unrelated disorders in patients with chronic medical diseases. $N$ Engl J Med. 1998;338(21):1516-1520.

19. Parchman ML, Romero RL, Pugh JA. Encounters by patients with type 2 diabetes - complex and demanding: an observational study. Ann Fam Med. 2006;4(1):40-45

20. SPSS. Version 13.0. Chicago, III: SPSS, Inc; 2003.

21. Raudenbush S, Bryk A, Congdon R. HLM: Hierarchical and Nonlinear Modeling (Version 6.0). Lincolnwood, III: Scientific Software International, Inc; 2004.

22. Callahan EJ, Bertakis KD. Development and validation of the Davis Observation Code. Fam Med. 1991;23(1):19-24.

23. Rodondi N, Peng T, Karter AJ, et al. Therapy modifications in response to poorly controlled hypertension, dyslipidemia, and diabetes mellitus. Ann Intern Med. 2006;144(7):475-484.

24. Giere R. Science Without Laws. Chicago, Ill: University of Chicago Press; 1999.

25. Miller WL, McDaniel RR Jr, Crabtree BF, Stange KC. Practice jazz: understanding variation in family practices using complexity science. J Fam Pract. 2001;50(10):872-878.

26. Helseth LD, Susman JL, Crabtree BF, O'Connor PJ. Primary care physicians' perceptions of diabetes management. A balancing act. J Fam Pract. 1999;48(1):37-42.

27. Hofer TP, Zemencuk JK, Hayward RA. When there is too much to do: how practicing physicians prioritize among recommended interventions. J Gen Intern Med. 2004;19(6):646-653.

28. Ostbye T, Yarnall KS, Krause KM, et al. Is there time for management of patients with chronic diseases in primary care? Ann Fam Med. 2005;3(3):209-214.

29. Grumbach K, Bodenheimer T. A primary care home for Americans: putting the house in order. JAMA. 2002;288(7):889-893. 